\title{
EXPERIMENTAL STUDY ON LAMINAR FLAME SPEEDS AND MARKSTEIN LENGTH OF PROPANE AIR MIXTURES AT ATMOSPHERIC CONDITIONS
}

\author{
A.A. Yousif ${ }^{1 *}$, S.A. Sulaiman ${ }^{1}$ and M.S. Nasif ${ }^{1}$ \\ ${ }^{1}$ Department of Mechanical Engineering, Universiti Teknology PETRONAS, \\ 31750 Bandar Seri Iskandar, Perak, Malaysia \\ *Email: a.altagyousif@gmail.com \\ Or: alatelecom76@yahoo.com \\ Phone: +60175829510
}

\begin{abstract}
An experimental study is performed in this work to determine stretched and unstretched laminar flame propagation velocities, Lewis number, flame thickness and the Markstein length of propane-air mixtures. The spherical flame propagation method was used to achieve this experimental work. Non-premixed propane-air mixtures at ambient temperature $303 \pm 1 \mathrm{~K}$, pressure of $0.1 \mathrm{MPa}$ and equivalence ratios ranging from $\Phi=0.6$ to 1.4 were ignited in a cylindrical combustion chamber. The stretched laminar burning speed was found to increase with the flame radius and time from ignition, which was attributed to flame propagation development. This is achieved by high-speed schlieren cine photography for observation of the flames in the vessel. The results obtained show that the unstretched laminar flame velocity increased as the equivalence ratio increased, and the recorded value reached a maximum at equivalence ratio $\Phi=1.0$ and decreased at the rich region. It was found that, with increase of the equivalence ratio, the Markstein length is increased and decreased in lean mixtures. The present data were in good agreement with those previously published using different techniques. However, the difference between the peak value of laminar flame velocity in the present work and those in the literature is between $4-5.5 \%$.
\end{abstract}

Keywords: Flame speed; laminar flame velocity; Markstein length; flame thickness.

\section{INTRODUCTION}

The design of most combustor tools needs data on various fundamental parameters such as: flame stabilization, emissions characteristics, auto-ignition, combustion dynamics, etc. These parameters are influenced by the fuel-air mixture properties [1], such as flame speed, ignition delay, minimum ignition energy, and flammability limits [2]. Laminar flame speed is one of the most important and considered basic properties of a combustible mixture and strongly affects the design parameters of the combustor [3]. Laminar flame speed also works as a global parameter which accounts for the diffusivity and reactivity of mixtures [4]. Furthermore, the data of laminar flame speed can be used to validate the chemical reaction mechanisms [5]. Propane is the main component of liquefied petroleum gas (LPG), which is one of the main energy sources in commercial applications and domestic usage [6]. Moreover, propane is a specific fuel for micro-energy devices. This is because it liquefies at low pressure and room temperature, and it is available in compact containers [7]. However, propane provides only $4 \%$ of the total energy needs of the world. Since 1992, the American National 
Energy Policy has approved propane as a clean fuel and listed it as an alternative fuel for vehicles due to its environmental benefits [8]. Previous researches have focused on a combined numerical and experimental investigation for laminar flame propagation of propane combustible mixtures with a mesoscale combustor, platinum-coated, which is a candidate for applications of moveable power generation [7,9]. The results showed that the metallic materials are better in terms of combustion efficiency, maximum thermal power output, flow velocity and the effect of wall thermal properties on flame propagation.

Various measurements were performed to accurately determine the laminar flame speed for different reactant mixtures [10-12]. A study by Kochar et al. [4] utilizing laminar flame speeds of $\mathrm{C}_{1}-\mathrm{C}_{3}$ alkanes at elevated pressure and temperature with dilution of $\mathrm{N}_{2}$ found that $\mathrm{CO}_{2}$ dilution decreased the flame speed more than the same amount of $\mathrm{N}_{2}$ dilution [13]. This is mainly due to the higher specific heat capacity of $\mathrm{CO}_{2}$ compared to $\mathrm{N}_{2}$. [11] reported measurements of laminar flame speed and alkane blends at elevated pressures. The results show a strong sensitivity to reactant temperature. Even a small increment in initial temperature (e.g., from $295 \mathrm{~K}$ to $305 \mathrm{~K}$ ) produces measurably higher flame speeds. [9] studied the diffusive thermal instabilities of $\mathrm{C}_{4} \mathrm{H}_{10}-\mathrm{C}_{3} \mathrm{H}_{8}$ /air laminar premixed flames using a burner plate. The flame is more disposed to cellular instabilities at low equivalence ratios. However, a different structure reaction is observed for propane fuel mixed with $\mathrm{H}_{2}$ and $\mathrm{CO}$ on a $\mathrm{V}$-shaped burner, regardless of the properties of pure propane [14]. The result shows that the lean flammability limit of propane- $\mathrm{H}_{2}$ increased to 0.38 and for propane-CO extended to 0.5 . [15] studied experimentally the determination of laminar flame speeds and counterflow ignition temperatures of $\mathrm{C}_{2}-\mathrm{C}_{3}$ hydrocarbons at ambient and high pressures, and the results showed that the present data agree well with those in the literature. The current work aimed to study the laminar flame speed, flame thickness and Markstein length of propane-air mixtures experimentally using a cylindrical combustion chamber in a wide range of equivalence ratios and under ambient conditions. It also presents the necessary experimental data and information on the laminar flame speeds for development and validation of physical model of combustor tools.

\section{METHOD AND MATERIALS}

\section{Mathematical Background}

By using the schlieren photography system, laminar flame velocity $S_{i}(\mathrm{~cm} / \mathrm{s})$ and burned gas Markstein lengths $L_{b}$ in mm can be derived as described in [6]. The stretched flame propagation speed $S_{b}$ in $\mathrm{m} / \mathrm{s}$ relative to the burned gases is obtained from the derivative of the flame radius versus the time by:

$$
S_{b}=\frac{d r}{d t}
$$

where $r$ represents the flame radius in mm observed by schlieren cine photography and $t$ is the elapsed time from spark ignition in ms. At any point of the flame surface, the total stretch rate of flame $\alpha$ in $S^{-1}$, which represents the expanding rate of the flame front area, is defined as Eq. (2).

$$
\alpha=\frac{d(\operatorname{Ln} A)}{d t}=\frac{1}{A} \frac{d A}{d t}=\frac{2}{r} S_{b}
$$


where $A$ is the area of the infinitesimal element of the flame surface in $\mathrm{mm}^{2}$. In respect to the early stage of flame propagation, there is a linear relationship between the stretched flame speeds and flame stretch rate:

$$
S_{b}=S_{u}-L_{b} \alpha
$$

where $S_{u}$ is the unstretched laminar flame propagation speed in $\mathrm{m} / \mathrm{s}$, which can be obtained as the intercept value of $S_{b}$ at stretch rate $\alpha=0$, in the plot of stretched flame speed $S_{b}$ against flame stretched rate $\alpha$. The negative value of the slope of stretched flame speed $S_{b}$ versus stretched rate $\alpha$ of the experimental data gives the burned gas Markstein length $L_{b}$. The quantity $L_{b}$ is defined as the effect of stretch on flame speed. From continuity and assuming that the flame is quasi-steady, the unstretched laminar burning velocity $S_{i}$ is deduced from $S_{u}$ using:

$$
S_{i}=S_{u}\left(\frac{\rho_{b}}{\rho_{u}}\right)
$$

where $\rho_{u}$ and $\rho_{b}$ are the unburned and burned densities of combustible mixtures in $\mathrm{kg} / \mathrm{m}^{3}$. The Lewis number $L_{e}$ is a dimensionless number, and defined as the ratio of the thermal diffusivity to binary mass diffusivity of the fuel and its oxidant. And this number plays a large role in the flame response for a given mixture and is defined as [16]:

$$
L_{e}=\frac{D t}{D u}=\frac{\lambda}{C_{p} \rho_{u} D_{u}}
$$

where $\lambda$ is the thermal conductivity in $\mathrm{W} / \mathrm{m} . \mathrm{K}, C_{p}$ is the specific heat at constant pressure of the unburned mixture in $\mathrm{kJ} / \mathrm{kg} \mathrm{K}, \rho_{u}$ is unburned density, and $D_{u}$ the binary mass diffusivity of fuel to diluents in $\mathrm{cm} / \mathrm{s}^{2}$.

\section{Experimental Setup}

The cylindrical explosion vessel used in the present work has an inner diameter of 360 $\mathrm{mm}$ and a length of $360 \mathrm{~mm}$. The explosion vessel was designed and fabricated to study the combustion of different laminar gaseous fuels. The vessel can resist the high pressure and temperature produced from the explosion of combustible mixtures. The explosion vessel was created from mild steel alloy which can tolerate initial pressures of 1.0 MPa. Two orthogonal quartz windows with a diameter of $150 \mathrm{~mm}$ and $25.4 \mathrm{~mm}$ thickness for the flame propagation inspection were fixed on both flat sides of the vessel. A type-K thermocouple was located inside the vessel to read the initial temperature of the combustible mixture. With a resolution of $0.00001 \mathrm{MPa}$, a digital pressure gage was located outside the chamber to monitor the pressure of the combustible mixture. Two electrodes facing each other were established at the center of the vessel with a $2 \mathrm{~mm}$ gap to create the ignition of the combustible mixture and the ignition was generated with a $12 \mathrm{~V}$ automotive ignition coil system. Two control valves were mounted on the chamber body for the inlet of propane and air mixture as well as for the exhaust gases. Fuel and dry air were injected into the explosion vessel through the inlet valve, with regard to their partial pressures. Experiments were performed at an initial temperature of $303 \mathrm{~K}$ and ambient pressure of $0.1 \mathrm{MPa}$. The propane fuel used in 
this study had a purity of $95.5 \%$, while the purified dry air had a purity of $99.995 \%$, as shown in Table 1. To ensure the homogeneity and motionlessness of the mixtures, the ignition was started after 10 minutes of the supply of the mixture and air.

The schematic diagram of the experimental setup is shown in Figure 1. A horizontal schlieren photography system setup was used to observe the growth of the flames front inside the chamber. A $50 \mathrm{~W}$ halogen lamp was used as a light source to provide the light through the pinholes. Other equipment included a high speed camera, two $120 \mathrm{~mm}$ diameter Plano convex lenses with a $1000 \mathrm{~mm}$ focal point, a condenser convex lens and two pinholes, with a diameter of $2 \mathrm{~mm}$. Images of flame front propagation were captured by using a high speed camera Phantom V9.2 with resolutions of 512 x 512, at a frame rate of 1000 fps. MATLAB code was used to process the resulting images and measure the radius of flame propagation. The light pixels in the flame images were converted to white, and dark pixels were converted to black. The radius of flames was measured as those of a circle area equal to that of the imaged flame.

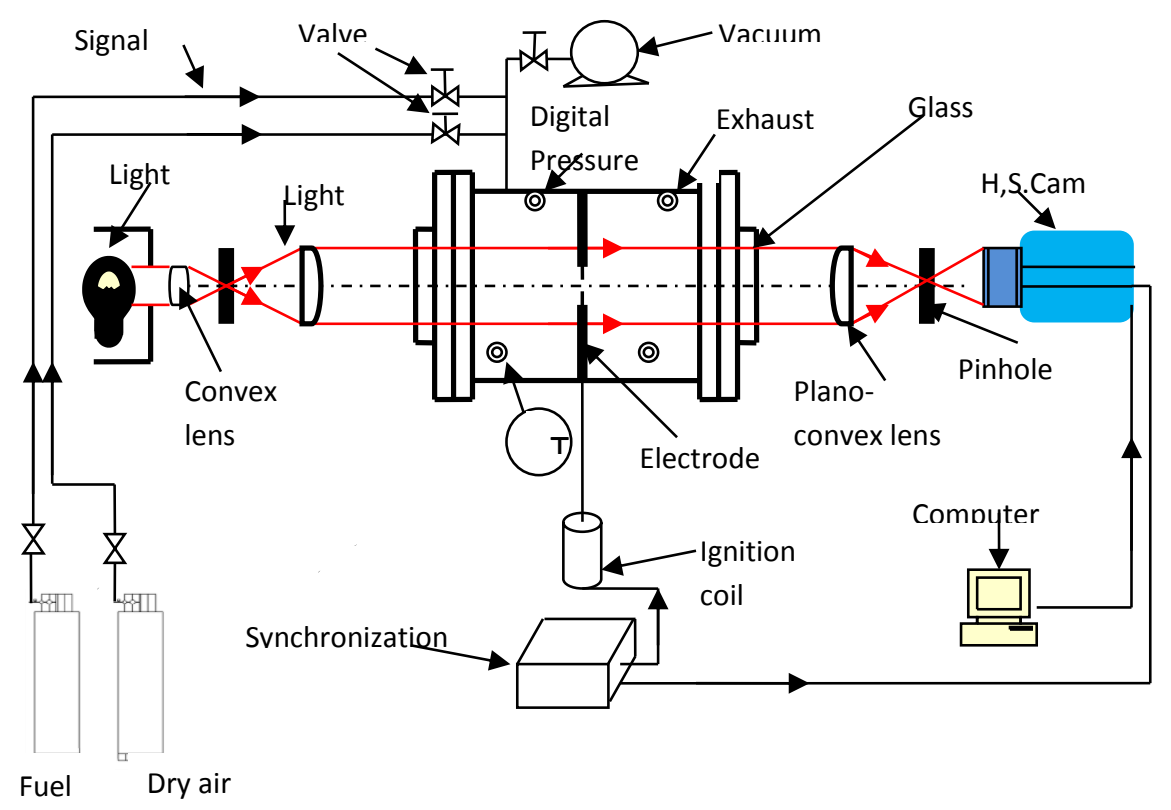

Figure 1. Schematic of the experiment setup.

Table 1. Mixture properties, Markstein length, Lewis number and flame thickness of $\mathrm{C}_{3} \mathrm{H}_{8}$-air mixtures.

\begin{tabular}{|c|c|c|c|c|c|c|c|}
\hline Mixtures & Purity $\%$ & $\Phi$ & $P$ (bar) & $T(\mathrm{~K})$ & $L_{e}$ & $L_{b}(\mathrm{~mm})$ & $\delta(\mathrm{mm})$ \\
\hline \multirow{3}{*}{$\mathrm{C}_{3} \mathrm{H}_{8}$} & \multirow{3}{*}{$95 \%$} & 0.6 & 1 & 303 & 1.707 & 2.327 & 0.106 \\
\hline & & 0.8 & 1 & 303 & 1.690 & 1.843 & 0.082 \\
\hline & & 0.9 & 1 & 303 & 1.681 & 1.788 & 0.058 \\
\hline \multirow{5}{*}{ Air } & \multirow{5}{*}{$99.995 \%$} & 1.0 & 1 & 303 & 1.663 & 1.673 & 0.049 \\
\hline & & 1.1 & 1 & 303 & 1.654 & 1.684 & 0.057 \\
\hline & & 1.2 & 1 & 303 & 0.975 & 1.660 & 0.064 \\
\hline & & 1.3 & 1 & 303 & 0.969 & 1.455 & 0.066 \\
\hline & & 1.4 & 1 & 303 & 0.963 & 1.139 & 0.102 \\
\hline
\end{tabular}




\section{Experimental Procedure}

The fuel and air were injected directly throughout the ports provided on the cylindrical vessel. The flow of propane fuel and air was controlled by stainless steel ball valves at the top of the combustion chamber. Propane and air were stored in high pressure steel cylinders. The propane and air were injected directly into the combustion chamber individually according to their partial pressures. Before the start of every test, the explosion vessel was purged with purified dry air for 10 minutes and evacuated up to a pressure of $0.00001 \mathrm{MPa}$ by using a rotary pump. Then the combustible mixture was prepared by filling the vessel with the required gases according to their appropriate partial pressures. After filling, the combustible mixture was left undisturbed for 15 minutes before starting the ignition to ensure complete mixing by diffusion of the fuel and air. In order to demonstrate the accuracy of the experimental analysis for the propane-air mixtures, data from three successive measurements were obtained. And the average flame radius was used to calculate the unstretched flame speeds, laminar flame velocities, flame thickness and Markstein length. All data obtained from the experiments are shown in Table 2.

\section{RESULTS AND DISCUSSION}

\section{Flame speed measurements}

In the present experimental investigations, Eqs. (1)-(5) were applied to determine the stretched and unstretched laminar flame speeds, laminar burning velocity, burned gas Markstein length, Lewis number and flame thickness of the propane-air mixtures. The experiments were conducted at atmospheric pressure and ambient temperature, over a wide range of equivalence ratios $(\Phi=0.6,0.8,0.9,1.0,1.1,1.2,1.3$ and 1.4). Forty frames of smooth flame images were used to determine the flame propagation from the ignition time and the vessel wall effect. As shown in Table 2, the measured flame radii for all mixtures were $2 \mathrm{~mm}$ and $53 \mathrm{~mm}$ as the minimum and maximum radius respectively.

Table 2. Summary of data reduction of $\mathrm{C}_{3} \mathrm{H}_{8-}$ air mixture at $0.1 \mathrm{MPa}$ and $303 \pm 1 \mathrm{~K}$.

\begin{tabular}{cccccccccc}
\hline$\Phi$ & $\begin{array}{c}r_{\min } \\
\mathrm{mm}\end{array}$ & $\begin{array}{c}r_{\max } \\
\mathrm{mm}\end{array}$ & $\begin{array}{c}\alpha_{\min } \\
\mathrm{S}^{-1} \times \\
1000\end{array}$ & $\begin{array}{c}\alpha_{\max } \\
\mathrm{S}^{-1} \times \\
1000\end{array}$ & $\begin{array}{c}S_{b} \text { at } \\
\alpha_{\min } \\
\mathrm{m} / \mathrm{s}\end{array}$ & $\begin{array}{c}S_{b} \text { at } \alpha \\
\max \\
\mathrm{m} / \mathrm{s}\end{array}$ & $\begin{array}{c}S_{u} \text { at } \\
\alpha=0 \\
\mathrm{~m} / \mathrm{s}\end{array}$ & $\rho_{b} / \rho_{u}$ & $S_{i} \mathrm{~cm} / \mathrm{s}$ \\
\hline 0.6 & 2.68 & 50.68 & 37 & 500 & 0.96 & 0.65 & 1.04 & 0.173 & 18.13 \\
0.8 & 2.90 & 52.5 & 57 & 500 & 1.50 & 0.72 & 1.61 & 0.143 & 23.13 \\
0.9 & 3.88 & 52.90 & 83 & 666 & 2.21 & 1.29 & 2.43 & 0.133 & 32.47 \\
1.0 & 3.74 & 52.21 & 105 & 667 & 2.75 & 1.24 & 3.02 & 0.127 & 38.50 \\
1.1 & 3.75 & 52.59 & 91 & 666 & 2.39 & 1.25 & 2.60 & 0.125 & 34.31 \\
1.2 & 2.65 & 51.41 & 68 & 666 & 1.77 & 0.88 & 1.89 & 0.126 & 32.54 \\
1.3 & 4.4 & 51.40 & 66 & 666 & 1.44 & 1.98 & 1.37 & 1.29 & 27.50 \\
1.4 & 2.49 & 49.48 & 48 & 500 & 1.21 & 0.62 & 1.37 & 0.130 & 17.38 \\
\hline
\end{tabular}

Figure 2 shows the images of propane-air flames at stoichiometric equivalence ratio $(\Phi=1.0)$, and an initial pressure and temperature of $0.1 \mathrm{MPa}$ and $303 \mathrm{~K}$ respectively were recorded and obtained by schlieren cine photography and the high- 
speed digital camera. The spherical flames propagated smoothly from the electrode gap in the center of the combustion chamber when the flame radius was developed to a confidence value $\mathrm{r}>3 \mathrm{~mm}$ and the effect of the electrodes then becomes negligible, since the flame propagates freely and becomes independent of the influence of the spark ignition and electrode.

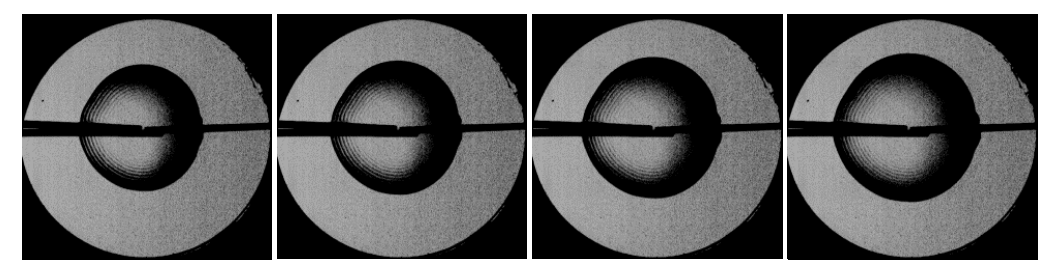

$\mathrm{t}=18 \mathrm{~ms}$

$\mathrm{t}=19 \mathrm{~ms}$

$\mathrm{t}=20 \mathrm{~ms}$

$\mathrm{t}=21 \mathrm{~ms}$

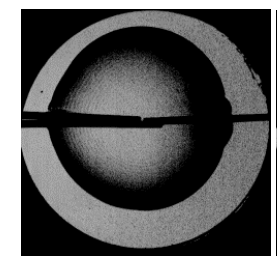

$\mathrm{t}=26 \mathrm{~ms}$
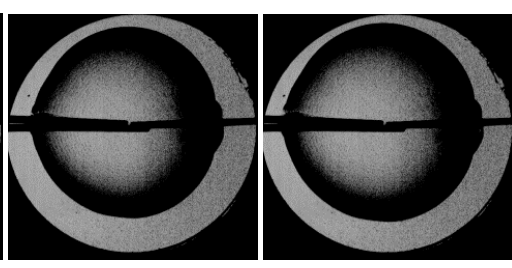

$\mathrm{t}=28 \mathrm{~ms}$

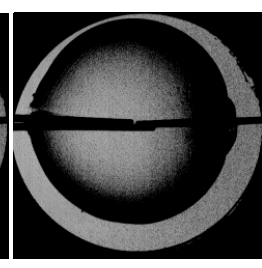

$\mathrm{t}=30 \mathrm{~ms}$

Figure 2. Flame images for propane-air mixtures at equivalence ratio $\Phi=1.0$.

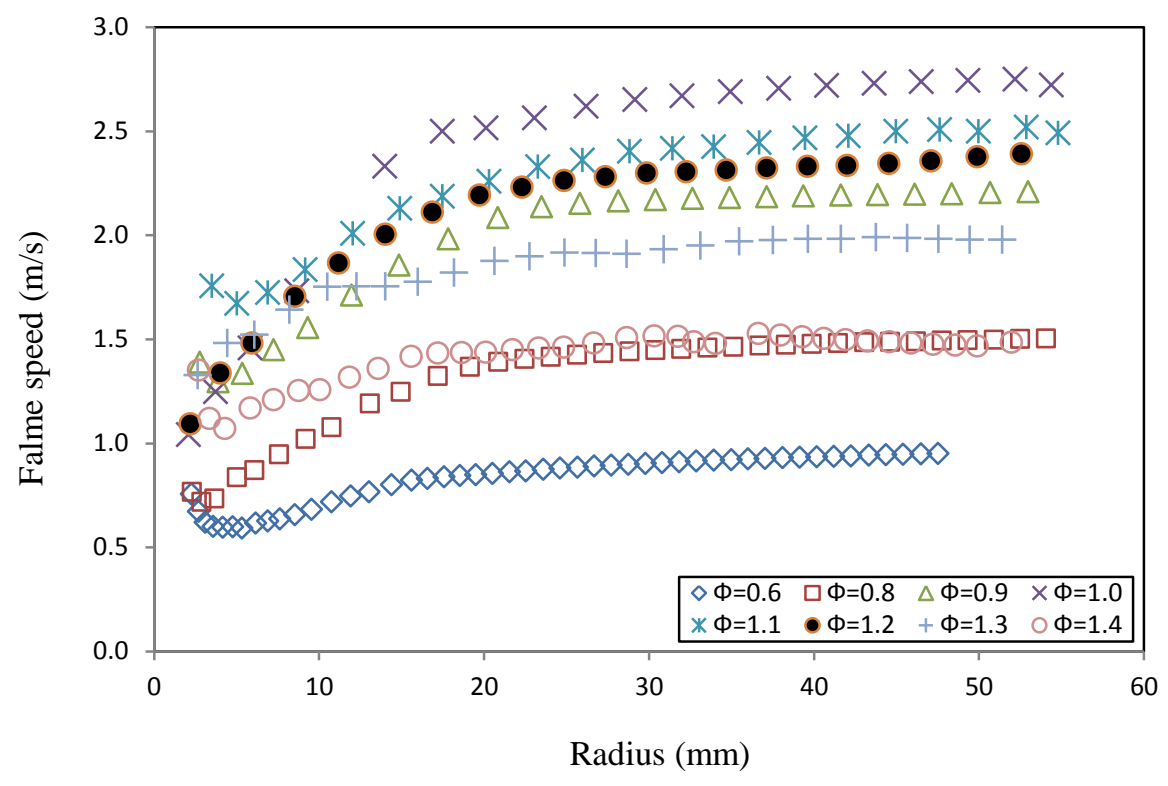

Figure 3. Flame speed versus flame radius at different equivalence ratios.

After ignition of the reactant mixture has occurred, the stretched flame front propagates outwardly smoothly from the electrode gap in the center of the vessel at a constant speed relative to the unburned mixtures. Figure 3 shows the relationship between the stretched flame propagation speed $S_{b}$ and flame radius $r$. The stretched flame speed can be obtained from the derivative of the flame radius and elapsing time. As shown in the figure, the stretched flame speed of the propane-air flames increases with increase of the equivalence ratio from $\Phi=0.6$ to 1.4. The peak value of flame speed was obtained at a stoichiometric mixture at $\Phi 1.0$, which is shifted to the rich 
mixture region for those in the literature, with the peak value obtained at $\Phi=1.1$. Moreover, this variation in the peak value is due to the propane's purity, which in the present work is $95.5 \%$.

Figure 4 shows variation of the stretched flame propagation speed with the flame stretch rate for the propane-air mixture at a wide range of equivalence ratios. For all the investigated mixtures, the flame propagation speed increased as the stretch rate decreased, and this indicates the appositive value of the Markstein length $L_{b}$. Furthermore, the equivalence ratio has the same influence on the development of the flame speed versus the stretch rate, and the maximum influence is observed in the stoichiometric mixture. Also, Figure 4 shows the application of the linear extrapolation method on the stretched flame propagation speed for propane-air mixtures at different equivalence ratios, to obtain the values of unstretched laminar flame speed and burned Markstein lengths. As is also shown in the figure, the linear method is suitable for all the investigated mixtures. The burned Markstein length values are positive for all mixtures, as shown in Table 1, which indicates that all the investigated mixtures have a stable flame speed, because the slope of the $S_{b}-\alpha$ fitting curve does not change to negative values.

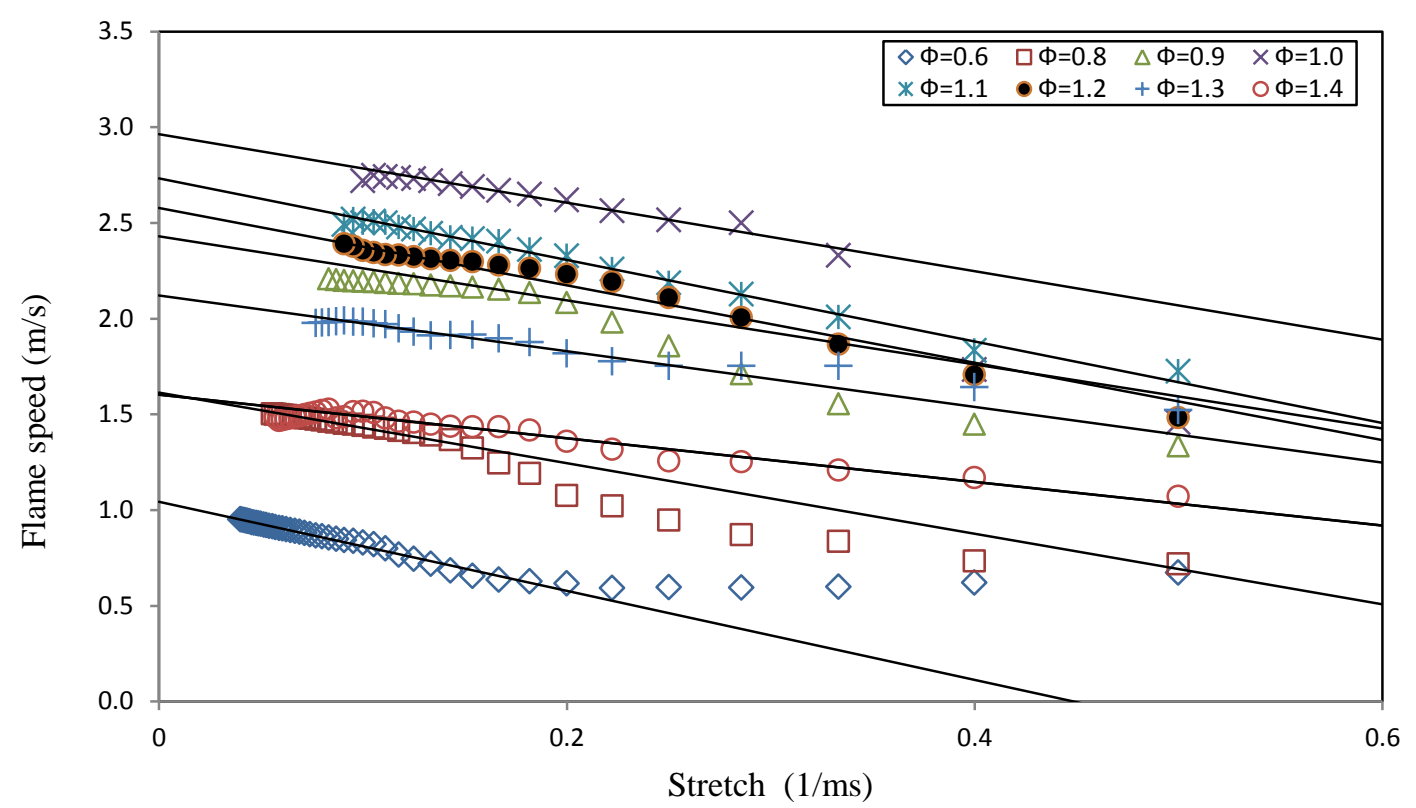

Figure 4. Flame stretch linear extrapolation versus stretch rate at different equivalence ratios.

Observation of the unstretched laminar burning velocity is shown in Figure 5, in which the linear extrapolation of laminar velocity is plotted and compared. Figure 5 shows the variation of measured laminar burning velocity for propane-air mixtures as a function of the fuel equivalence ratio at $303 \mathrm{~K}$ and $0.1 \mathrm{MPa}$. With increase in the fuel equivalence ratios, the values of laminar burning velocity increased and the greatest value was obtained at the equivalence ratio $\Phi=1.0$.

To validate the accuracy of the present work, a comparison was made between the present results and experimental work conducted using different methods by [11], [17], [2], [18], [19], [20] and [21]. The the data measurements and those from the literature were found to be in good agreement in the case of lean to stoichiometric 
mixtures, but there was some difference in rich mixtures with [21]. This difference occurred due to the configuration methods used and the purity of the propane in the combustible mixtures. However, the difference between the values of laminar burning velocity in the present work and those in the literature is between $4-5.5 \%$.

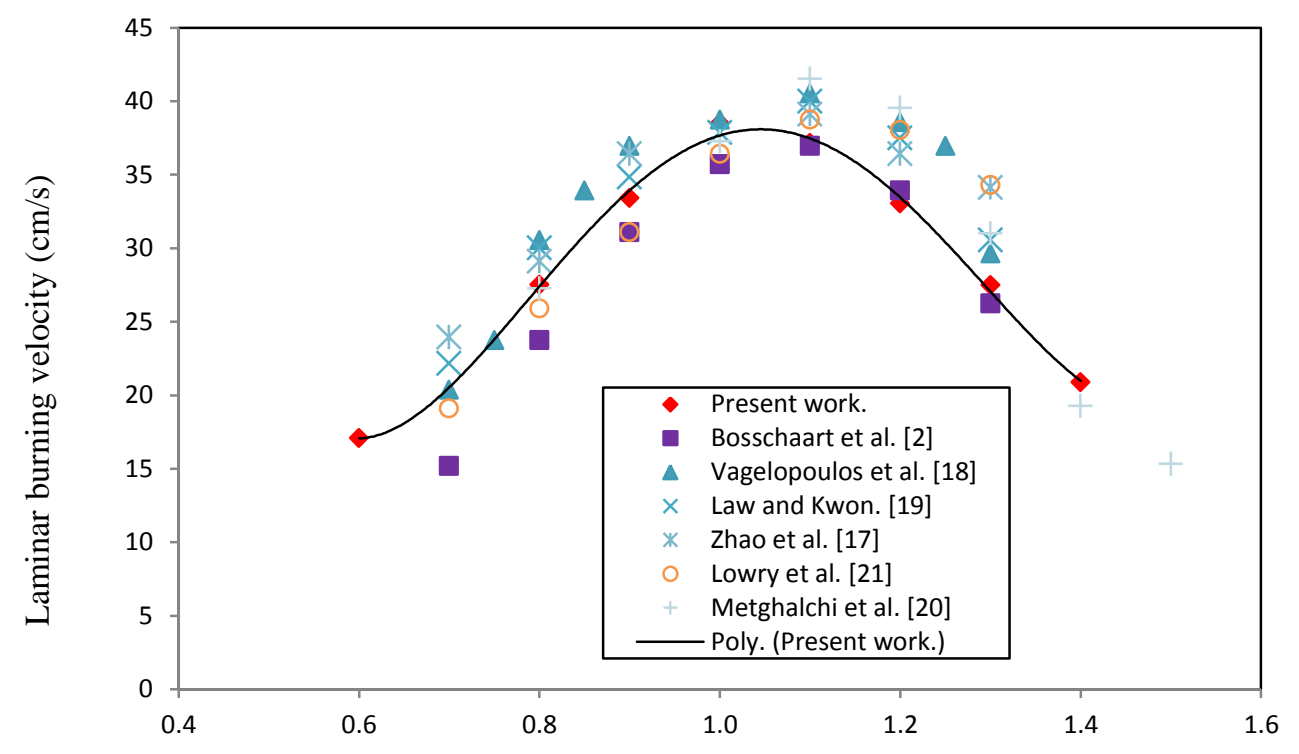

Equivalence ratio

Figure 5. Laminar flame velocity versus equivalence ratio of propane-air mixtures.

\section{Markstein length, Lewis number and flame thickness}

The Markstein length is defined as the slope of the straight line fit of Eq. (3). The measured gas Markstein lengths $L_{b}$ with all equivalence ratios mixtures for propane-air flames are illustrated in Figure 6. The Markstein length of the burned gas is an indicator of flames stability with respect to the preferential diffusion effect of the mixtures. As shown in Figure 6 for all propane-air mixtures, the Markstein length shows a decreasing trend with increase of the equivalence ratio. This indicates that the flames of most mixtures support stable flames with reference to the diffusion mechanism. A comparison of burned Markstein length $L_{b}$ in the present work with others in the literature shows good agreement with previous measurements reported by [22], [23], [24], and [19], for propane-air mixtures, as shown in Figure 6. For all propane-air mixtures, the Markstein lengths $L_{b}$ are positive and this indicates a positive value of Lewis number $L_{e}$, as provided in Table 1. Moreover, increase of the Lewis number causes increase of the Markstein length $L_{b}$.

Figure 7 shows the flame thickness of the propane-air mixtures, which were measured in the present investigation, compared to experimental data obtained by [25]. The flame thickness $\delta$ of the propane-air flames was calculated using the thermal diffusivity method, by applying the relation: $\delta=\left(D_{t} / S_{i}\right)$, where $D_{t}$ is the thermal diffusivity. The results of the present work, and those obtained by [25] using a different method, indicated clearly that the flame thickness of the propane-air mixtures decreased with increase of the equivalence ratio, and the minimum value of flame thickness was found to be $\Phi=1.1$. 


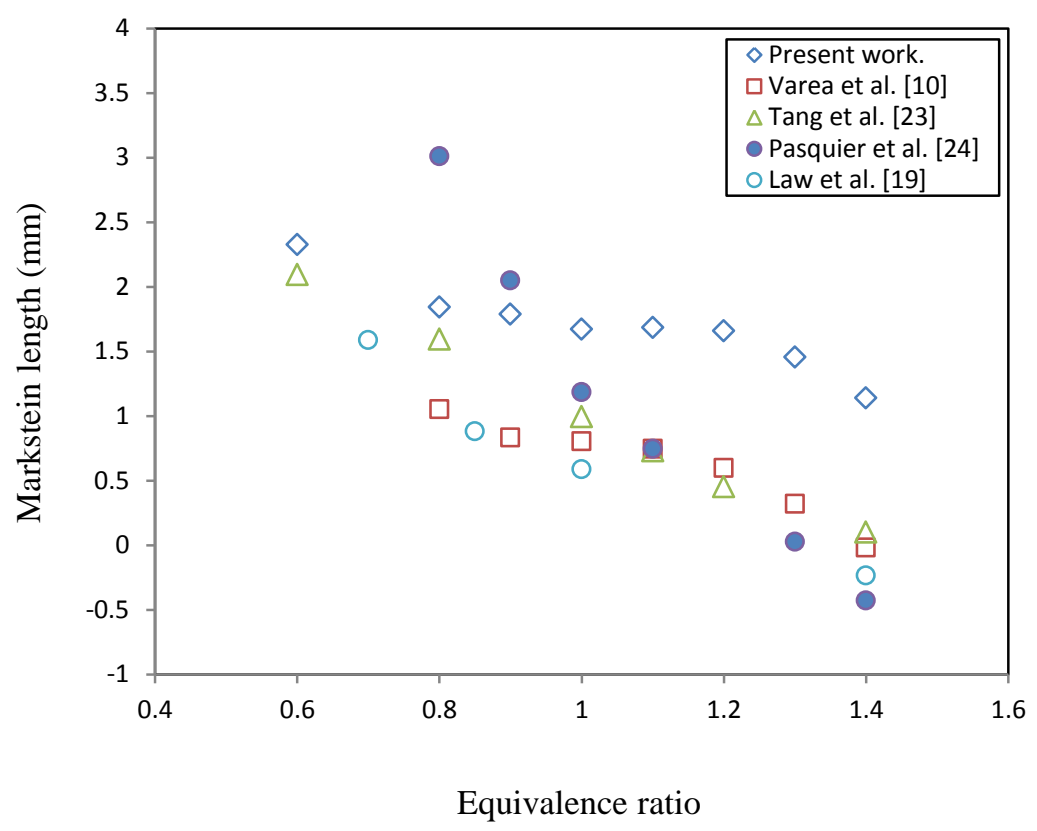

Figure 6. Burned gas Markstein lengths vs equivalence ratio of propane-air mixtures.

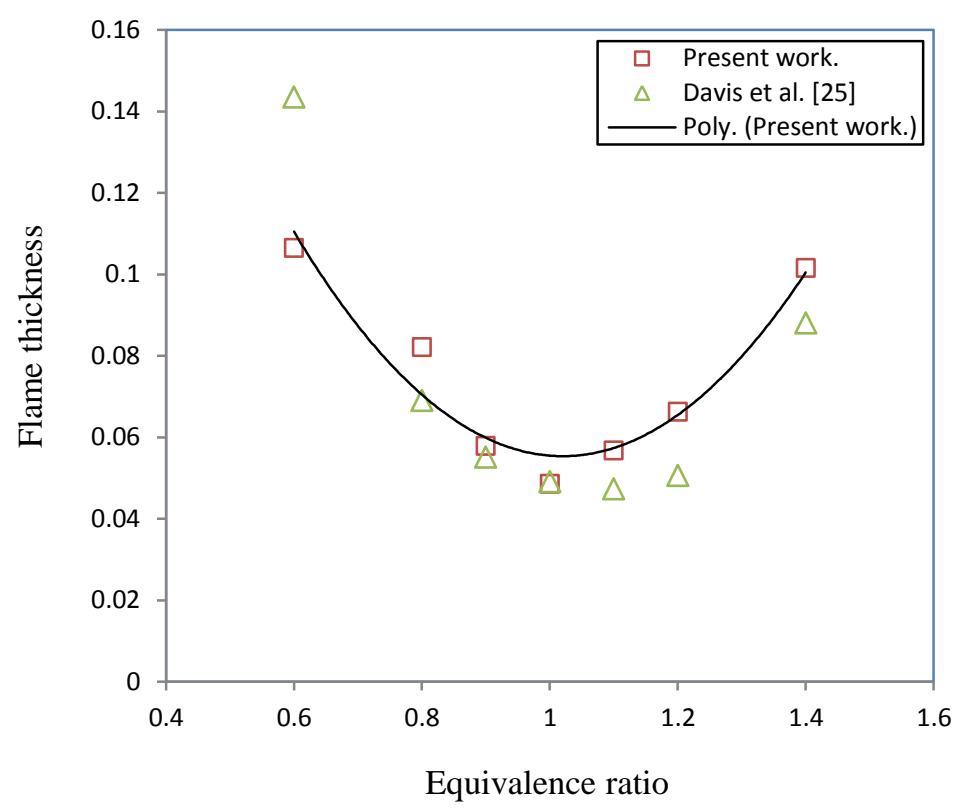

Figure 7. Flame thickness vs equivalence ratio of propane-air mixtures.

\section{CONCLUSIONS}

In the current investigation the stretch effects on laminar flame velocities of propane-air mixtures were investigated experimentally over a wide range of equivalence ratios, and at ambient temperature and atmospheric pressure. To determine the laminar flame speeds of propane-air mixtures, the technique of spherically expanding flame was applied. Flame stability was observed for all mixtures at ambient conditions from lean to rich mixtures. The measured unstretched laminar flame speeds increase with increasing equivalence ratios, and the peak value shifts to the stoichiometric mixtures 
side. The values obtained were compared with reported results obtained using different computational experimental and techniques. In general, the agreement is good. For propane-air mixtures, the Markstein lengths were found to increase with the equivalence ratios and decreased in the lean region. By using the thermal diffusivity method, the flame thicknesses for all mixtures were calculated and compared.

\section{ACKNOWLEDGEMENTS}

The authors would like to be grateful to express their appreciation to Universiti Teknology PETRONAS for providing fund, support and laboratory facilities to this work.

\section{REFERENCES}

[1] Noor M, Wandel AP, Yusaf $T$. Effect of air-fuel ratio on temperature distribution and pollutants for biogas MILD combustion. International Journal of Automotive and Mechanical Engineering. 2014;10:1980-92.

[2] Bosschaart KJ, De Goey L. The laminar burning velocity of flames propagating in mixtures of hydrocarbons and air measured with the heat flux method. Combustion and Flame. 2004;136:261-9.

[3] Hu E, Huang Z, He J, Jin C, Zheng J. Experimental and numerical study on laminar burning characteristics of premixed methane-hydrogen-air flames. International Journal of Hydrogen Energy. 2009;34:4876-88.

[4] Kochar. Y TL, J. Seitzman. Laminar Flame Speeds of $\mathrm{C}_{1}-\mathrm{C}_{3}$ Alkanes at Elevated Pressure and Temperature with Dilution. presented at the Proceedings of the 6th US National Combustion Meeting. 2009.

[5] Yu Cheng CT, Zuohua Huang. Kinetic analysis of $\mathrm{H}_{2}$ addition effect on the laminar flame parameters of the C1-C4 n-alkane-air mixtures: From one step overall assumption to detailed reaction mechanism. International Journal of Hydrogen Energy. 2015;40:703-18.

[6] Miao J, Leung C, Huang Z, Cheung C, Yu H, Xie Y. Laminar burning velocities, Markstein lengths, and flame thickness of liquefied petroleum gas with hydrogen enrichment. International Journal of Hydrogen Energy. 2014;39:13020-30.

[7] $\mathrm{Ju} \mathrm{Y}, \mathrm{Xu}$ B. Theoretical and experimental studies on mesoscale flame propagation and extinction. Proceedings of the Combustion Institute. 2005;30:2445-53.

[8] NPGA. Facts about Propane. American's Exceptional Energy. 4.1.2001.

[9] Abdulwahid M, M Saqr K, M Sies M, Ujir H. Diffusive thermal instabilities of $\mathrm{C}_{4} \mathrm{H}_{10}-\mathrm{C}_{3} \mathrm{H}_{8} /$ air laminar premixed flames. The Open-Access Journal for the Basic Principles of Diffusion Theory, Experiment and Application. 2009;9:1-8.

[10] Varea E, Modica V, Vandel A, Renou B. Measurement of laminar burning velocity and Markstein length relative to fresh gases using a new postprocessing procedure: Application to laminar spherical flames for methane, ethanol and isooctane/air mixtures. Combustion and Flame. 2012;159:577-90.

[11] Yash Kochar JSaTL, Wayne Metcalfe, Sineas Burke and Henry Curran, Michael Krejci, William Lowry and Eric Petersen, Gilles Bourque. Laminar Flame Speed Measurements and Modeling of Alkane Blends at Elevated Pressures with Various Diluents. ASME Turbo Expo. 2011. 
[12] Karagiannidis S, Marketos K, Mantzaras J, Schaeren R, Boulouchos K. Experimental and numerical investigation of a propane-fueled, catalytic mesoscale combustor. Catalysis Today. 2010;155:108-15.

[13] Kumaran P, Gopinathan M, Kantharrajan S. Combustion Characteristics of Improved Biodiesel in Diffusion Burner. International Journal of Automotive and Mechanical Engineering. 2014;10:2112-2121.

[14] Chen JW, Chui CP, Mo SH, Yang JT. Combustion characteristics of premixed propane flame with added $\mathrm{H}_{2}$ and $\mathrm{CO}$ on a $\mathrm{V}$-shaped impinging burner. International Journal of Hydrogen Energy. 2015;40:1244-55.

[15] Jomaas G, Zheng X, Zhu D, Law C. Experimental determination of counterflow ignition temperatures and laminar flame speeds of $\mathrm{C}_{2}-\mathrm{C}_{3}$ hydrocarbons at atmospheric and elevated pressures. Proceedings of the Combustion Institute. 2005;30:193-200.

[16] Sun C, Sung C, He L, Law C. Dynamics of weakly stretched flames: quantitative description and extraction of global flame parameters. Combustion and Flame. 1999;118:108-28.

[17] Zhao Zhenwei AK, Juan Li, and Frederick L. Dryer. The initial temperature and $\mathrm{n}_{2}$ dilution effect on the laminar flame speed of propane/air. Combustion Science and Technology. 2004;176: 1705-23.

[18] Vagelopoulos CM, Egolfopoulos FN. Direct experimental determination of laminar flame speeds. Symposium (international) on combustion. 1998;513-9.

[19] Law C, Kwon O. Effects of hydrocarbon substitution on atmospheric hydrogenair flame propagation. International Journal of Hydrogen Energy. 2004;29:86779.

[20] Metghalchi M, Keck J. Laminar burning velocity of propane-air mixtures at high temperature and pressure. Combustion and Flame. 1980;38:143-54.

[21] Lowry WS, Zeynep Bourque, Gilles Metcalfe, Wayne de Vries, Jaap Krejci, Michael Curran, Henry Petersen, Eric. Laminar flame speed measurements and modeling of pure alkanes and alkane blends at elevated pressures. Journal of Engineering for Gas Turbines and Power. 2011;133:091501.

[22] Varea E. Experimental analysis of laminar spherically expanding flames: INSA de Rouen; 2013.

[23] Tang C, He J, Huang Z, Jin C, Wang J, Wang X, et al. Measurements of laminar burning velocities and Markstein lengths of propane-hydrogen-air mixtures at elevated pressures and temperatures. International Journal of Hydrogen Energy. 2008;33:7274-85.

[24] Pasquier N, Lecordier B, Trinite M, Cessou A. An experimental investigation of flame propagation through a turbulent stratified mixture. Proceedings of the Combustion Institute. 2007;31:1567-74.

[25] Davis S, Quinard J, Searby G. Markstein numbers in counterflow, methane-and propane-air flames: a computational study. Combustion and Flame. 2002;130:123-36. 